УДК 371.3

https://doi.org/10.36906/AP-2020/03

\title{
ИНФОРМАТИКА КАК ПРОФЕССИОНАЛЬНО-ОРИЕНТИРОВАННАЯ ДИСЦИПЛИНА В СИСТЕМЕ ПОДГОТОВКИ БАКАЛАВРОВ
}

\author{
Казиахмедов Т. Б. \\ канд. пед. наук \\ Нижневартовский государственный университет \\ г. Нижневартовск, Россия
}

\begin{abstract}
Аннотация. Анализ содержания дисциплины «Информатика» в системе подготовки бакалавров по различным направлениям показывает, что в основном упор делается на изучение технологий решения задач обработки информации, хотя информатика как наука имеет вполне определенный инвариант. В статье исследуются подходы в разрешении этой проблемы. Особенно важным является рассмотрение изучения различных наук информатики в системе подготовки бакалавров по IT направлениям. Необходимо вернуться к изучению проблематики разработки трансляторов, компиляторов, отечественных СУБД, операционных систем, других инструментальных средств разработки программного обеспечения.
\end{abstract}

Ключевые слова: информатика как наука и технология, операционные системы, профессионально-ориентированная дисциплина.

В данной работе предлагается рассмотреть информатику как учебную дисциплину, определив назначение, цели, задачи, компетенции, формируемые данной дисциплиной.

Назначение «Информатики» (цели обучения информатике):

- получение базовых знаний о способах представления, хранения, обработки и передачи информации, о современных информационных технологиях, о возможности использования методов математического моделирования в исследованиях в профессиональной деятельности (химии, биологии, физики, математики, филологии и т.д);

- раскрытие сути и возможности технических и программных средств информатики, возможности и способов применения компьютерных технологий в обучении и научноисследовательской деятельности;

- ознакомление с наиболее часто используемыми прикладными программными комплексами, программами статистической обработки данных и получение основных навыков работы с ними;

- формирование целостного представления об информатике и ее роли в развитии общества;

- формирование способности самостоятельно приобретать и применять новые знания и умения;

- получение навыков использования инструментария сетевого общения, программных комплексов дистанционного взаимодействия.

В практике обучения информатике в вузах России приняты компетенции, отраженные в таблице 1: 


\begin{tabular}{|c|c|}
\hline $\begin{array}{c}\text { Профессиональные компетениии } \\
\text { (ПК) }\end{array}$ & Содержание компетенции \\
\hline $\begin{array}{l}\text { умеет работать с компьютером } \\
\text { на уровне пользователя и } \\
\text { способен применять навыки } \\
\text { работы с компьютерами, как в } \\
\text { социальной сфере, так и в } \\
\text { области познавательной и } \\
\text { профессиональной деятельности }\end{array}$ & $\begin{array}{l}\text { знать: основы каждой из рассматриваемых } \\
\text { компьютерных технологий; основные возможности } \\
\text { вычислительных систем; устройство и принципы } \\
\text { обработки информации системами мультимедиа; уметь: } \\
\text { работать с компьютером на уровне пользователя и } \\
\text { применять навыки работы в учебной и научно- } \\
\text { исследовательской деятельности; владеть: навыками } \\
\text { работы с программными комплексами, с банками данных } \\
\text { в области проф. деятельности, в локальных и глобальных } \\
\text { сетях. }\end{array}$ \\
\hline $\begin{array}{l}\text { способен понимать сущность и } \\
\text { значение информации в развитии } \\
\text { современного информационного } \\
\text { общества, сознавать опасности и } \\
\text { угрозы, возникающие в этом } \\
\text { процессе, соблюдать основные } \\
\text { требования информационной } \\
\text { безопасности, в том числе } \\
\text { защиты государственной тайны }\end{array}$ & $\begin{array}{l}\text { знать: основные теоретические концепции предмета; } \\
\text { основные тенденции развития современных } \\
\text { информационных технологий и основы каждой из } \\
\text { рассматриваемых компьютерных технологий, основы } \\
\text { информационной безопасности, современные } \\
\text { антивирусные программы; уметь: работать в локальной и } \\
\text { глобальной вычислительных сетях с соблюдением } \\
\text { политики информационной безопасности; владеть: } \\
\text { практическими навыками работы с информацией с } \\
\text { использованием компьютерных систем (с соблюдением } \\
\text { политики безопасности). }\end{array}$ \\
\hline $\begin{array}{l}\text { владеет основными методами, } \\
\text { способами и средствами } \\
\text { получения, хранения, } \\
\text { переработки информации, имеет } \\
\text { навыки работы с компьютером, } \\
\text { как средством управления } \\
\text { информацией }\end{array}$ & $\begin{array}{l}\text { знать: принципы организации, основные технические } \\
\text { средства компьютерных систем; основы каждой из } \\
\text { рассматриваемых компьютерных технологий; основные } \\
\text { возможности вычислительных систем; устройство и } \\
\text { принципы обработки информации системами } \\
\text { мультимедиа; уметь: использовать современные } \\
\text { компьютерные технологии (технологии обработки } \\
\text { данных, текстовой, графической, числовой информации, } \\
\text { сетевые и мультимедиа технологии) в учебной и научно- } \\
\text { исследовательской деятельности; владеть: методами } \\
\text { получения, представления и обработки информации (в } \\
\text { том числе в информационных сетях). }\end{array}$ \\
\hline $\begin{array}{l}\text { способен работать с } \\
\text { информацией в глобальных } \\
\text { компьютерных сетях }\end{array}$ & $\begin{array}{l}\text { знать: функциональные возможности и принципы } \\
\text { организации информационных сетей; принцип } \\
\text { организации и работы поисковых систем; уметь: } \\
\text { использовать средства телекоммуникационного доступа к } \\
\text { источникам научной информации, возможности сети } \\
\text { Internet; владеть: навыками работы в поисковых } \\
\text { системах, с тематическими каталогами; навыками } \\
\text { сайтостроения и работы в off-line и on-line режимах. }\end{array}$ \\
\hline
\end{tabular}




\begin{tabular}{|c|c|}
\hline $\begin{array}{c}\text { Профессиональные компетенции } \\
\text { (ПК) }\end{array}$ & Содержание компетенциии \\
\hline $\begin{array}{l}\text { использует основные законы } \\
\text { естественнонаучных дисциплин } \\
\text { в профессиональной } \\
\text { деятельности, применяет методы } \\
\text { математического анализа и } \\
\text { моделирования, теоретического } \\
\text { и экспериментального } \\
\text { исследования }\end{array}$ & $\begin{array}{l}\text { знать: основы программирования, основные типы } \\
\text { алгоритмов, основы моделирования; уметь: использовать } \\
\text { методы математического моделирования (с } \\
\text { использованием пакетов программ обработки данных), } \\
\text { готовые прикладные программные комплексы в } \\
\text { предметной области и смежных наук; владеть: навыками } \\
\text { работы с наиболее часто используемыми прикладными } \\
\text { программными комплексами; навыками структурного } \\
\text { программирования, построения эмпирических моделей с } \\
\text { использованием пакетов программ статистической } \\
\text { обработки данных, имитационного моделирования при } \\
\text { решении проблем предметной области (например, } \\
\text { химической технологии и экологии; физики и } \\
\text { электроники, электротехники, педагогики и психологии, } \\
\text { филологии). }\end{array}$ \\
\hline $\begin{array}{l}\text { способен применять основные } \\
\text { законы научной дисциплины } \\
\text { (например, химии, биологии, } \\
\text { географии, физики) при } \\
\text { обсуждении полученных } \\
\text { результатов, в том числе с } \\
\text { привлечением информационных } \\
\text { баз данных }\end{array}$ & $\begin{array}{l}\text { знать: виды программного обеспечения, которое можно } \\
\text { было бы использовать в научной и профессиональной } \\
\text { деятельности, системы сбора, обработки и хранения } \\
\text { информации из области проф. деятельности; уметь: } \\
\text { пользоваться стандартными банками компьютерных } \\
\text { программ и банками данных; владеть: навыками работы с } \\
\text { базами данных. }\end{array}$ \\
\hline $\begin{array}{l}\text { Способен использовать методы } \\
\text { регистрации и обработки } \\
\text { результатов экспериментов в } \\
\text { сфере проф. деятельности }\end{array}$ & $\begin{array}{l}\text { знать: виды программного обеспечения, которое можно } \\
\text { было бы использовать в научной и профессиональной } \\
\text { деятельности, системы сбора, обработки и хранения } \\
\text { информации из профессиональной сферы; уметь: } \\
\text { анализировать результаты математической обработки } \\
\text { научных данных с целью определения их достоверности } \\
\text { и области использования; владеть: навыками работы с } \\
\text { наиболее часто используемыми прикладными } \\
\text { программными комплексами; методами представления и } \\
\text { обработки результатов исследований; навыками } \\
\text { использования пакетов программ статистической } \\
\text { обработки данных, имитационного моделирования при } \\
\text { обработке результатов исследований. }\end{array}$ \\
\hline
\end{tabular}

Содержание дисциплины «Информатика» должно быть следующим (оптимальное содержание и разделы курса):

- Вычислительная техника.

- Теоретические основы информатики. Кодирование информации.

- Логические основы компьютеров. Алгебра логики.

- Программное обеспечение компьютера.

- Информационные системы и технологии. 


\section{СОВРЕМЕННОЕ ПРОГРАММИРОВАНИЕ}

III Международная научно-практическая конференция

- Операционные системы (ОС).

- Прикладное программное обеспечение.

- Технологии обработки текстовой, графической и числовой информации.

- Сетевые и телекоммуникационные технологии. Гипертекстовые системы в обучении.

- Защита информации.

- Основы программирования. Алгоритмы.

- Моделирование и формализация. Классификация моделей и решаемых на их базе задач.

- Использование программных продуктов для отображения результатов исследований из проф. области (химии, биологии, экологии, физики, электротехники и др).

- Визуализация данных. Компьютерная презентация.

- Базы данных.

- Прикладные программы для предметной области, в том числе компоненты ГИС и цифровых карт.

- Математические пакеты программ.

Трудоемкость дисциплины «Информатика» приведена в нижеследующей таблице 2.

Таблица 2

\begin{tabular}{|c|c|}
\hline Вид учебной работы & Всего часов(з.е.) \\
\hline Общая трудоемкость дисциплины & $324(9$ 3.e. $)$ \\
\hline Лекции & 36 \\
\hline Практические работы & 72 \\
\hline Самостоятельная работа: & 180 \\
\hline $\begin{array}{l}\text { В том числе: } \\
\text { Творческая работа (реферат, проекты компьютерной } \\
\text { презентации, Web-странички) }\end{array}$ & 120 \\
\hline $\begin{array}{l}\text { Другие виды самостоятельной работы } \\
\text { (домашние работы, консультации по е-mail, } \\
\text { общение в on-line режиме, подготовка к к/p и коллоквиуму, } \\
\text { зачету, экзамену) }\end{array}$ & 60 \\
\hline Вид промежуточного контроля & $\begin{array}{l}\text { Тест, контрольная работа (к/p), } \\
\text { коллоквиум. } \\
\text { Для проверки работы в сети } \\
\text { предусмотрены консультации } \\
\text { по е-mail, общение в on-line } \\
\text { режиме. } \\
\text { Защита Web проекта(1семестр), } \\
\text { подготовленной компьютерной } \\
\text { презентации (обучающей } \\
\text { программы) (2 семестр), } \\
\text { оценка рефератов }\end{array}$ \\
\hline Вид итогового контроля & $\begin{array}{l}1 \text { семестр - зачет (итоговый } \\
\text { тест, устный опрос); } \\
2 \text { семестр - экзамен (итоговый } \\
\text { тест, устный ответ на вопросы } \\
\text { билета) }\end{array}$ \\
\hline
\end{tabular}


Далее рассмотрим, как происходит подготовка IT специалистов. Прежде всего, подготовка должна сопровождаться опережающим обучением [1].

Разработаны методические рекомендации по изучению баз данных в школе в разделе информатики и ИКТ «Программирование» [2], а также в системе подготовки бакалавров и магистров по направлению 44.04.01-Педагогическое образование, профиль — информатика [3].

Ориентируясь на опережающий подход, в 2019/2020 учебном году было запланировано обновление названий дисциплин и их содержания. При опережающем подходе подготовки IT специалистов должен быть ориентир - на решение следующих глобальных задач:

- Сетевые операционные системы (подходы к разработке и разработка ОС).

- Отечественные СУБД и банки данных.

- Компиляторы. Трансляторы. Визуальные среды разработки ИС.

- Интеллектуальные ИС для различных научных и экономических сфер.

- Отечественный управляемый сегмент Интернет.

- Система облачных сервисов (удешевление услуг и ПО).

- Системы компьютерного перевода.

- Автоматизация и роботизация производственных процессов и услуг.

Для внедрения в систему подготовки IT бакалавров были запланированы дисциплины, внедренные уже в 2019/2020 учебном году (отмечены курсивом):

- Разработка систем управления базами данных.

- Анализ и проектирование информационных систем.

- Компьютерные сети.

- Методология расчета ресурсов ЭВМ и сетей для ИС.

- Разработка клиент-серверных Wеb-приложений.

- Программирование микроконтроллеров и робототехники.

- Разработка графических пакетов автоматического проектирования (САПР),

- Программирование мобильных устройств.

- Разработка эмуляторов и трансляторов.

- Компьютерная лингвистика.

- Разработка распределенных информационных систем.

- Администрирование серверов, данных (Web сервер, сервер баз данных, файловый сервер).

- Прикладные модули системь 1 .

Для дальнейшей реализации опережающего подхода необходимо внедрить в учебные планы, указанные выше дисциплины (не выделены курсивом), а также и другие дисциплины:

- Информатика и основы компьютерных знаний (Информатика знаний).

- Использование языка С\# в различных информационных технологиях.

- Интеллектуальные системы принятия решений и управления.

- Основы информационной безопасности.

- Методы и средства хранения и защиты компьютерной информации.

- Персональные компьютеры в системах управления и автоматизации технологических процессов. информации.

- Регулирование, управление и принятие решений в условиях нечеткой

— Разработка приложений баз данных на основе современных технологий. 


\section{СОВРЕМЕННОЕ ПРОГРАММИРОВАНИЕ}

III Международная научно-практическая конференция

Основываясь на вышеизложенном, можно сделать вывод, что необходимо расширить курсы по выбору по IT направлениям следующими дисциплинами:

- Математические методы распознавания образов (Нейронные сети и технологии в распознавании образов).

- Математические методы анализа эффективности компьютерных сетей.

- Мехатроника.

- Основы электроники и робототехники (Элементная база и физические принципы разработки образовательных роботов).

- Математика и экспертные информационные системы.

- Графы и деревья в задачах поиска и сортировки на больших массивах данных (BigData).

- Научные исследования с использованием математических программных пакетов.

\section{Литература}

1. Казиахмедов Т. Б. Опережающее обучение в области индустрии информационных технологий в условиях развивающейся экономики и перманентных реформ высшего образования // Педагогическая информатика. 2014. №4. С. 62-72.

2. Казиахмедов Т. Б. Обучение учащихся профильной школы основам баз данных в курсе «Программирование» // Омские научные чтения-2019: Материалы Третьей Всероссийской научной конференции. 2019. С. 120-122.

3. Казиахмедов Т. Б. Проблемы и перспективы подготовки бакалавров и магистров по IT-направлениям в вузе // Современное программирование: Материалы II Международной научно-практической конференции. Нижневартовск: Нижневартовский государственный университет, 2019. С. 7-11.

(СКазиахмедов Т. Б., 2020 